\title{
DIAGNÓSTICO DA MORTALIDADE DE PEDESTRES NOS ESTADOS BRASILEIROS: ASPECTOS DEMOGRÁFICOS
}

\author{
G. P. Caldeira' ${ }^{1}$; B. P. Branco ${ }^{1,2}$; J. T. Bastos ${ }^{1,3}$ \\ ${ }^{1}$ Universidade Federal do Paraná, Rua Evaristo F. F. da Costa, 418, Jd. das Américas, Curitiba/PR \\ ${ }^{2}$ Observatório Nacional de Segurança Viária, R. 9 de Julho, 1953, Vila Georgina, Indaiatuba \\ gabrielcaldeira@ufpr.br', beatriz.branco@onsv.org.br ${ }^{2}, j t b a s t o s @ u f p r . b r^{3}$
}

Resumo: Dado o cenário de mortalidade no trânsito com uma elevada participaçáo dos pedestres do total de mortes no trânsito no Brasil, esta pesquisa tem por objetivo analisar esta situação e construir um diagnóstico da mortalidade de pedestres nos estados brasileiros, com destaque para os contrastes regionais em relação aos aspectos demográficos. Destacam-se as maiores taxas de mortes de pedestres nas faixas etárias entre 20 e 29 anos e 60 anos ou mais.

Palavras-chave: Pedestres, Mortalidade, Estados brasileiros.

\section{Introdução}

No meio urbano brasileiro as condições de circulação dos pedestres são, em geral, precárias e não há uma rede de transporte a pé com níveis adequados de segurança e conveniência $[1 ; 2]$. As viagens a pé em 2014 representaram 36,5\% das viagens realizadas nas cidades [3] - o que leva a necessidade de construir um diagnóstico da mortalidade em âmbito estadual.

\section{Metodologia}

A metodologia incluiu a coleta de dados secundários estaduais no período 2000-2015 referentes a vítimas fatais em atropelamentos (DATASUS) [4] e a população (IBGE) [5] e posterior análise comparativa dos dados.

\section{Resultados esperados/Conclusóes}

A partir da análise da taxa de óbitos de pedestres por 100 mil habitantes conforme faixa etária destacam-se os estados com elevadas taxas para a faixa etária dos 20 aos 29 anos (AL, ES, MA, MG, PB, PE, PR, RJ, RS e SP) e os estados com elevadas taxas para a faixa dos 60 anos ou mais (CE, GO, MG, PE, PR, RJ, RS, SE, SP e TO, com destaque para AC, AM, DF, PA, RO e RR). A elevada taxa para as faixas de 60 anos ou mais e de 20 a 29 anos é uma característica comum para a maioria dos estados, muito provavelmente devido aos comportamentos de risco mais recorrentes na faixa mais jovem anos e à maior vulnerabilidade associada aos usuários idosos. A taxa de óbitos de pedestres 
por 100 mil habitantes é de aproximadamente 4 a 6 vezes superior para os homens em relaçáa às mulheres.

\section{Referências}

[1] GOLD, Philip (Brasil). Qualidade de Calçadas no Município de São Paulo. São Paulo: Gold Projects, 2004.

[2] VASCONCELLOS, Eduardo Alcântara de. Políticas de Transporte no Brasil: A construção da mobilidade excludente. Barueri: Manole, 2014. 289 p.

[3] ASSOCIAÇÃO NACIONAL DE TRANSPORTES PÚBLICOS (ANTP) (Brasil) (Org.). Relatório Geral 2014. São Paulo, 2016. 96 p.

[4] BRASIL. Ministério da Saúde. Sistemas de Informaçôes de Mortalidade - DATASUS. Mortes por causas externas no período 2000-2015. Disponível em: <http://www2.datasus.gov.br/DATASUS>. Acesso em: 10 ago. 2017.

[5] BRASIL. Ministério do Planejamento Orçamento e Gestâo. Instituto Brasileiro de Geografia e Estatística IBGE. Populaçăo no Brasil de 2000-2015. Disponível em: <https://ww2.ibge.gov.br/home/estatistica/populacao>. Acesso em: 10 ago. 2017. 